\title{
Designing Higher Surface Area Metal-Organic Frameworks: Are Triple Bonds Better Than Phenyls?
}

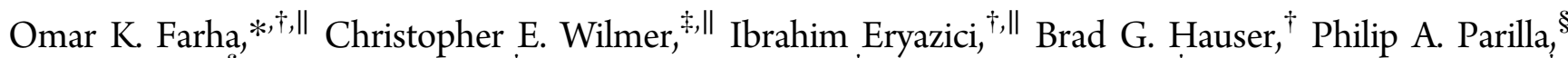
Kevin O’Neill, ${ }^{\S}$ Amy A. Sarjeant, ${ }^{\dagger}$ SonBinh T. Nguyen, ${ }^{\dagger}$ Randall Q. Snurr, ${ }^{*}+$ and Joseph T. Hupp ${ }^{* \dagger}$

\begin{abstract}
${ }^{\dagger}$ Department of Chemistry and International Institute for Nanotechnology, Northwestern University, 2145 Sheridan Road, Evanston, Illinois 60208-3113, United States

${ }^{\ddagger}$ Department of Chemical \& Biological Engineering, Northwestern University, 2145 Sheridan Road, Evanston, Illinois 60208-3120, United States

${ }^{\S}$ National Renewable Energy Laboratory, Golden, Colorado 80401, United States
\end{abstract}

Supporting Information

ABSTRACT: We have synthesized, characterized, and computationally validated the high Brunauer-EmmettTeller surface area and hydrogen uptake of a new, noncatenating metal-organic framework (MOF) material, NU-111. Our results imply that replacing the phenyl spacers of organic linkers with triple-bond spacers is an effective strategy for boosting molecule-accessible gravimetric surface areas of MOFs and related high-porosity materials.

$\mathrm{T}$ he chemical and structural diversity of metal-organic frameworks (MOFs) is one of the most notable characteristics of these materials. MOFs are hybrid materials composed of inorganic nodes and organic struts. ${ }^{1-3}$ The most intriguing examples exhibit large internal surface areas; ultralow densities; uniform channels, cavities, and voids; and permanent porosity. Because of these exceptional properties, MOFs are being investigated for many potential applications, including gas storage, ${ }^{4-8}$ gas and chemical separations, ${ }^{9-12}$ chemical catalysis, ${ }^{13,14}$ sensing, ${ }^{15}$ ion exchange, ${ }^{16}$ drug delivery, ${ }^{17}$ and light harvesting. ${ }^{18,19}$ Furthermore, the availability of singlecrystal structures of MOFs allows the use of computational modeling to calculate guest adsorption capabilities and other properties, which can help in screening MOFs for particular applications and improving our understanding of their performance. $^{20}$ The fact that these computational methods can be usefully applied gives MOFs a significant advantage over their amorphous counterparts.

Rising concerns about climate change have intensified the search for environmentally friendly and renewable fuels such as water-derived $\mathrm{H}_{2}$, cellulosic ethanol, and photo- or electrochemically generated methane. Although molecular hydrogen is a compelling alternative to gasoline in many respects, highdensity storage is a significant challenge for the viability of hydrogen-powered vehicles. In order to drive 300 miles, 5 to 13 $\mathrm{kg}$ of $\mathrm{H}_{2}$ are needed. Therefore, technologies that can efficiently concentrate gases at lower pressures, such as adsorption on porous materials, are desirable. The U.S. Department of Energy (DOE) has set targets for on-board $\mathrm{H}_{2}$ storage systems for the year 2017: 5.5 wt \% in gravimetric capacity and $40 \mathrm{~g} / \mathrm{L}$ of volumetric capacity at an operating temperature in the range -40 to $60{ }^{\circ} \mathrm{C}$ under a maximum delivery pressure of $100 \mathrm{~atm} .{ }^{21}$ Recently, automobile manufacturer Mercedes-Benz has announced its intention to use MOFs for mobile hydrogen storage at cryogenic temperatures. ${ }^{22}$ Required are materials with surface areas of $\sim 24$ million square feet of surface area per pound $\left(4900 \mathrm{~m}^{2} / \mathrm{g}\right)$ and the ability to store substantial hydrogen at $435 \mathrm{psi}$ (30 bar). MOFs are powerful contenders relative to other porous materials in meeting these conditions.

We set out to make a MOF that satisfies both of the aforementioned requirements $\left(\sim 4900 \mathrm{~m}^{2} / \mathrm{g}\right.$ and high hydrogen uptake at 30 bar). We turned our attention to $(3,24)$ paddlewheel-connected MOF networks ( $r h t$ topology), ${ }^{23}$ for which catenation (interpenetration or interweaving of multiple frameworks) is impossible. The use of this topology was pioneered by Eddaoudi ${ }^{23}$ and has been used by us ${ }^{24}$ and the Zhou $^{25}$ and Schröder ${ }^{26}$ groups. Recently, a MOF denoted as either PCN-69 ${ }^{27}$ or NOTT-119 ${ }^{28}$ with the rht topology was synthesized by both the Zhou and Schroder groups. PCN-69/ NOTT-119 has a Brunauer-Emmett-Teller (BET) surface area of $\sim 4000 \mathrm{~m}^{2} / \mathrm{g}$ and is made from the phenyl-based strut $\mathbf{L H}_{\mathbf{6}}(\mathbf{1})$ (Scheme 1). Even though $\mathbf{L H}_{\mathbf{6}}(\mathbf{1})$ is longer than

Scheme 1. Hexacarboxylic Acid Struts Used To Construct PCN-69/NOTT-119 $\left[\mathrm{LH}_{6}(1)\right]$, NOTT-112 $\left[\mathrm{LH}_{6}(2)\right]$, and NU-111 $\left[\mathrm{LH}_{6}(3)\right]$

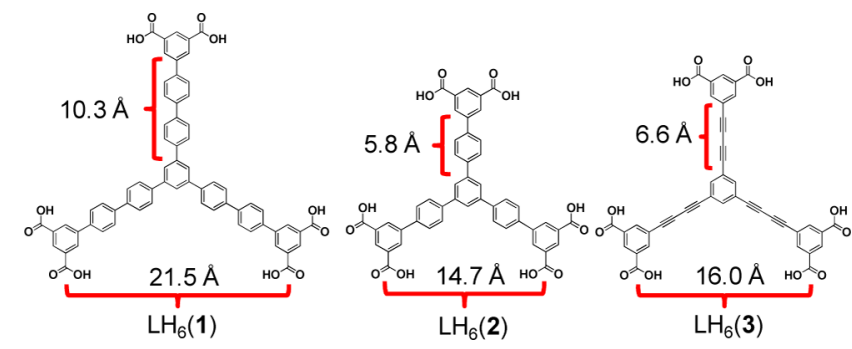

$\mathrm{LH}_{6}(2)$, the strut used to make NOTT-112 ${ }^{26}\left(3800 \mathrm{~m}^{2} / \mathrm{g}\right)$, the surface area of PCN-69/NOTT-119 did not increase significantly. To date, the best known strategy for obtaining

Received: March 17, 2012

Published: June 7, 2012 
higher-surface-area MOFs has been to use longer linkers. ${ }^{24,29}$ However, as the case of PCN-69/NOTT-119 shows, it is not only the length of the linker but also the shape and density that matter for high surface area.

With the above considerations in mind, we decided to replace the two phenyl spacers in each arm of the linker in PCN-69/NOTT-119 with two triple-bond spacers. Our initial notions were based on hypothetically exposing the edges of phenyl spacers by dividing each linker arm into three individual but chemically linked pieces, each consisting of two carbon atoms linked by a triple bond. These pieces are equivalent to acetylenes, but with carbon-carbon single bonds to neighboring pieces replacing the terminal hydrogen atoms. Thus, six linked alkynes would replace two linked phenyl groups. Given the synthetic challenge presented by the corresponding trigonal linker, however, we chose instead to start by replacing each phenyl spacer in $\mathbf{L H}_{6}(\mathbf{1})$ by one carbon-carbon triple bond.

In this report, we describe the synthesis and properties of a new MOF, NU-111 (NU = Northwestern University), formed from the new hexacarboxylic acid linker $\mathrm{LH}_{6}(3)$ that contains three pairs of triple-bond spacers. The synthesis and characterization of $\mathbf{L H}_{6}(3)$ is described in the Supporting Information (SI). Briefly, $\mathbf{L H}_{6}(3)$ was obtained via saponification of the corresponding hexaester precursor, which in turn was obtained via Sonogashira coupling of 1,3,5-triiodobenzene with 1,3diethoxycarbonyl-5-(butadiynyl)benzene.

Solvothermal reactions of $\mathrm{LH}_{6}(3)$ and $\mathrm{Cu}\left(\mathrm{NO}_{3}\right)_{2} \cdot 2.5 \mathrm{H}_{2} \mathrm{O}$ in $\mathrm{DMF} / \mathrm{EtOH} / \mathrm{HCl}(\mathrm{DMF}=$ dimethylformamide $)$ at $80^{\circ} \mathrm{C}$ gave MOFs with the framework formula $\left[\mathrm{Cu}_{3}(\mathrm{~L}(3))\left(\mathrm{H}_{2} \mathrm{O}\right)_{3}\right]_{n}$ in $75 \%$ yield after $48 \mathrm{~h}$. X-ray analysis of single crystals of NU-111 revealed a noncatenated structure with a cubic space group, $F m \overline{3} m$, in which the framework nodes consist of $\mathrm{Cu}_{2}{ }_{2}$ units coordinated by the carboxylates of $\mathbf{L}(3)^{6-}$ in paddlewheel fashion (Figure 1A,B). The axial sites of the $\mathrm{Cu}_{2}^{\mathrm{II}}$ units are coordinated by water molecules that were well-resolved in the $\mathrm{X}$-ray analysis. The experimental structure has unit-cell dimensions of $a=b=c=48.9 \AA$ at $225 \mathrm{~K}$. NU-111 can be represented using three types of space-filling polyhedra (also termed cages) that are derived from drawing straight lines between copper paddlewheels (Figure $2 \mathrm{~B}-\mathrm{D}$ column 1) and are fused in such a way that they form continuous channels (Figure 2E). The smallest cage is cuboctahedral and is formed from 24 isophthalate groups from $\mathrm{L}(3)^{6-}$ units and 12 pairs of copper ions (Figure 2B). The second cage is a truncated tetrahedron and is formed from isophthalate groups from four $\mathbf{L}(3)^{6-}$ linkers and 12 pairs of copper ions (Figure $2 \mathrm{C}$ ). The largest cage can be described as a truncated cuboctahedron and is formed by $24 \mathrm{Cu}_{2}{ }^{\mathrm{II}}$ paddlewheel nodes and portions of eight distinct $\mathbf{L}(3)^{6-}$ units (Figure $2 \mathrm{D}$ ). However, there is no unique representation of a MOF in the form of space-filling polyhedra, and the scheme described above, though both common and useful for $r h t$ topologies, neglects an important feature of NU111: a fourth cavity that can be detected experimentally (Figure $1 \mathrm{C}$, blue). An alternate choice of space-filling polyhedra can lead to greater physical insight; in this case, taking the curvature of the ligand into account gives four types of polyhedral cages, each corresponding to one of the four experimentally discovered cavities (Figure 2A-D column 2 and Figure 2F). Therefore, there are two ways of describing the topological features of NU-111 (see Figures S21 and S22 in the SI). The phase purity of a bulk sample of NU-111 was established via powder X-ray diffraction (PXRD) measurements since the simulated PXRD pattern was found to be in excellent

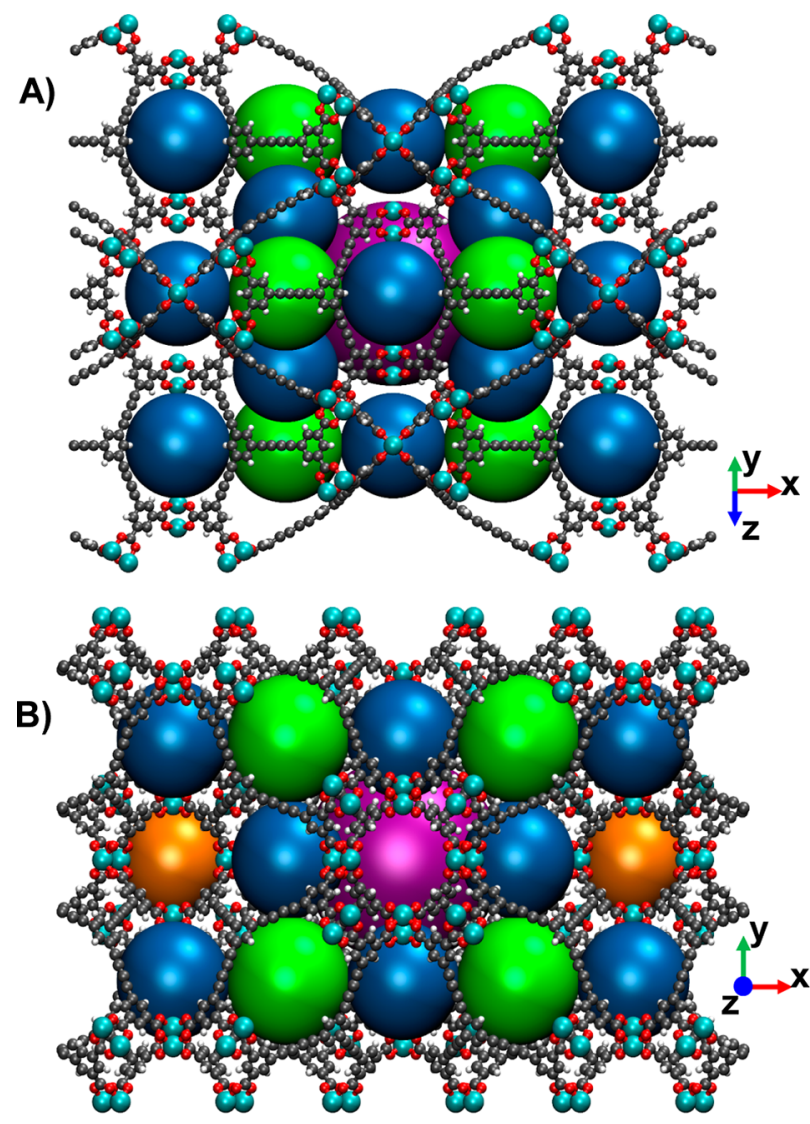

C)

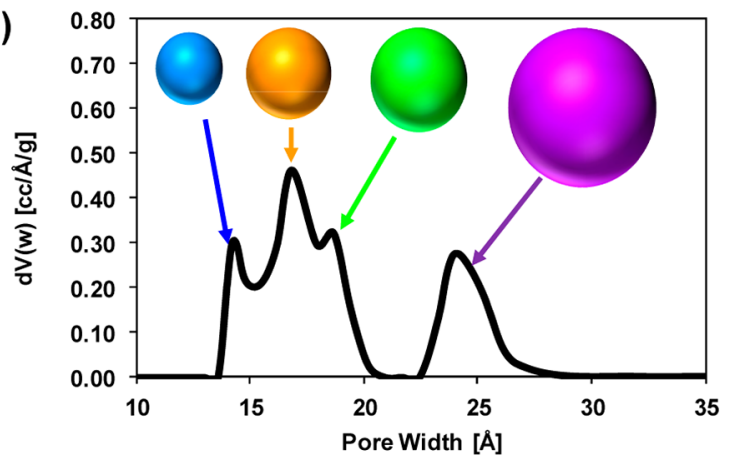

Figure 1. (A, B) Structurally derived views of NU-111. (C) Calculated pore size distribution of NU-111 based on experimental Ar adsorption at $87 \mathrm{~K}$. DFT kernel used: Ar at $87 \mathrm{~K} \_$zeolites/silica (cylindrical pore, NLDFT equilibrium model).

agreement with the experimental one (Figure S11). Additionally, thermogravimetric analysis (TGA) of NU-111 revealed a mass loss at $\sim 135{ }^{\circ} \mathrm{C}$ assigned to solvent (DMF), and no further mass loss occurred until $\sim 300{ }^{\circ} \mathrm{C}$ (Figure S12).

After the guest solvent molecules were removed using supercritical $\mathrm{CO}_{2}{ }^{29-33}$ (see the SI for activation details), the porosity was examined by nitrogen adsorption at $77 \mathrm{~K}$. The experimental and simulated $\mathrm{N}_{2}$ isotherms were in excellent agreement, as shown in Figure 3A. The experimental BET surface area of NU-111 was found to be $5000 \pm 80 \mathrm{~m}^{2} / \mathrm{g}$, which is higher than that of PCN-69/NOTT-119 (3989/4118 $\mathrm{m}^{2} / \mathrm{g}$ ). It is worth mentioning that the experimental BET surface area is in excellent agreement with that determined from the computationally simulated isotherm $\left(4915 \mathrm{~m}^{2} / \mathrm{g}\right)$. The total experimental pore volume of NU-111 is $2.38 \mathrm{~cm}^{3} / \mathrm{g}$. The pore size distribution of NU-111, calculated from Ar 
Cages

A)<smiles>c1ccccc1</smiles>

Column 1

Column 2

B)
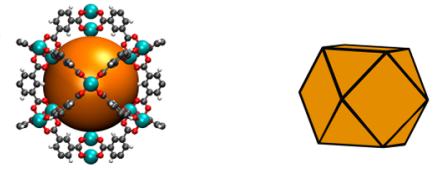

C)
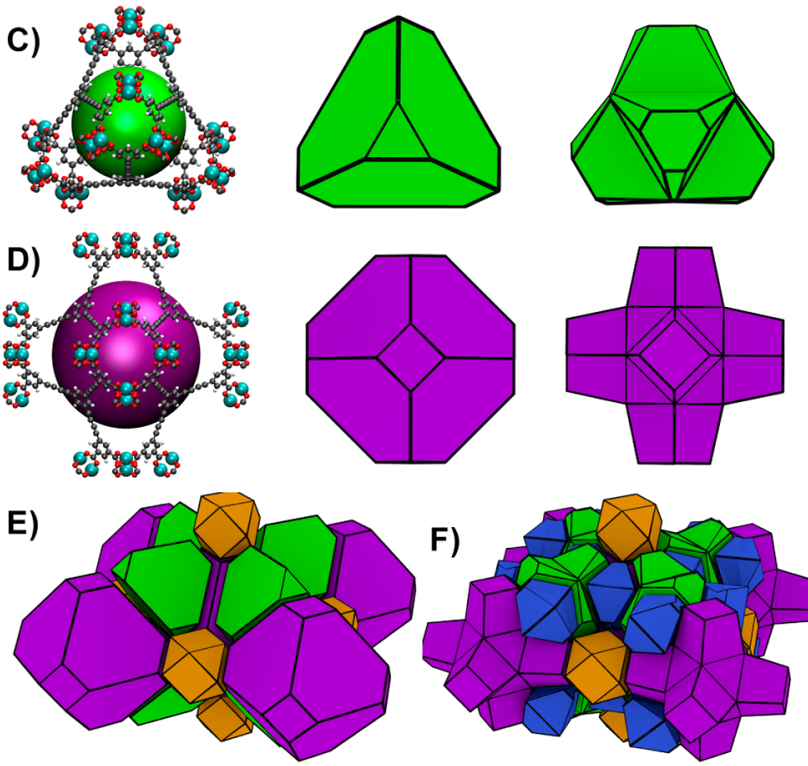

Figure 2. (A-D) Polyhedra in NU-111 obtained by drawing straight lines between the copper paddlewheels (column 1) and by taking into account the curvature of the ligands (column 2). (E, F) Packing of the polyhedra shown in (E) column 1 and $(\mathrm{F})$ column 2. Color code: $\mathrm{Cu}$, teal; $\mathrm{C}$, gray; $\mathrm{O}$, red; $\mathrm{H}$, white.

adsorption experiments at $87 \mathrm{~K}$ using nonlocal density functional theory (NLDFT), shows peaks at 14, 17, 19, and $24 \AA$ (Figure 1C), in excellent agreement with a geometric calculation based on the crystal structure (Figure S19).

The large surface area and pore volume of NU-111 prompted us to measure its high-pressure hydrogen capacity. These measurements were done at the DOE Hydrogen Sorption Center of Excellence at the National Renewable Energy Laboratory (NREL). Sorption data for $\mathrm{H}_{2}$ were collected up to 110 bar at $77 \mathrm{~K}$. It should be noted that only the "excess" gas adsorption is directly accessible experimentally. Excess gas adsorption is the amount adsorbed as a result of the presence of the adsorbent. The total adsorption is the sum of the excess adsorption and the amount that would be found within the pore volume, on the basis of the finite bulk-phase density of the gas, if the adsorbent were not present. For gas storage and delivery purposes, the total amount adsorbed is the more relevant quantity. The excess hydrogen uptake of NU111 was $21 \mathrm{mg} / \mathrm{g}$ at $1 \mathrm{bar}$ and $69 \mathrm{mg} / \mathrm{g}$ at $32 \mathrm{bar}$ (Figure 3B and Figure S23). From the $\mathrm{N}_{2}$-derived pore volume $\left(2.38 \mathrm{~cm}^{3} /\right.$ g) and the bulk phase density of $\mathrm{H}_{2}$, the total $\mathrm{H}_{2}$ uptake at 110 bar and $77 \mathrm{~K}$ was calculated to be $135 \mathrm{mg} / \mathrm{g}$ (Figure 3C). The uptake of NU-111 is within range of the DOE's revised longterm systems target for onboard $\mathrm{H}_{2}$ storage, 5.5 wt \% $(58 \mathrm{mg}$ / $\mathrm{g}$ ), albeit at cryogenic rather than ambient temperature. The simulated $\mathrm{H}_{2}$ isotherm of NU-111 was in only qualitative

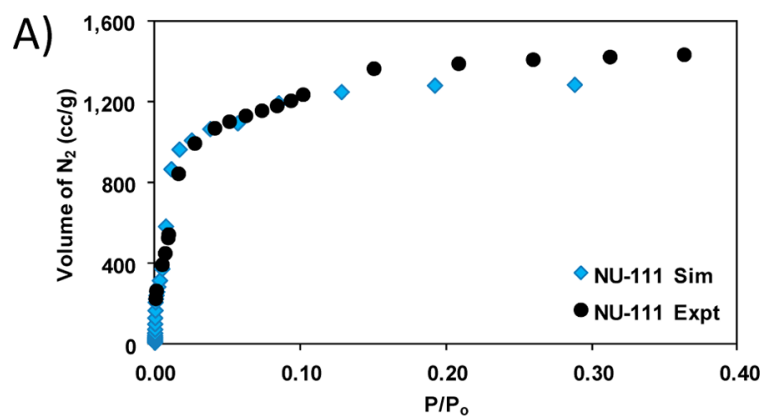

B)

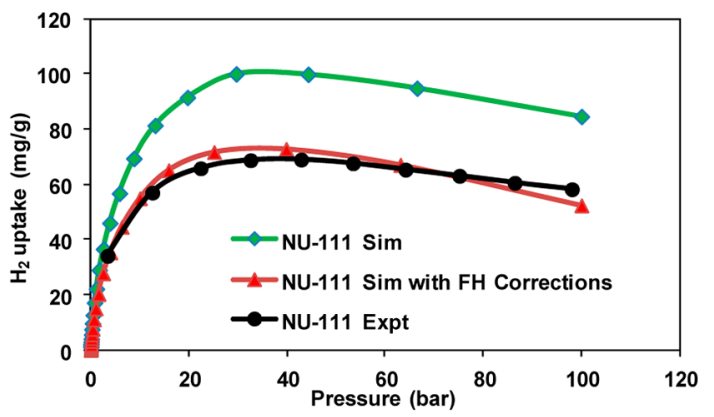

C)

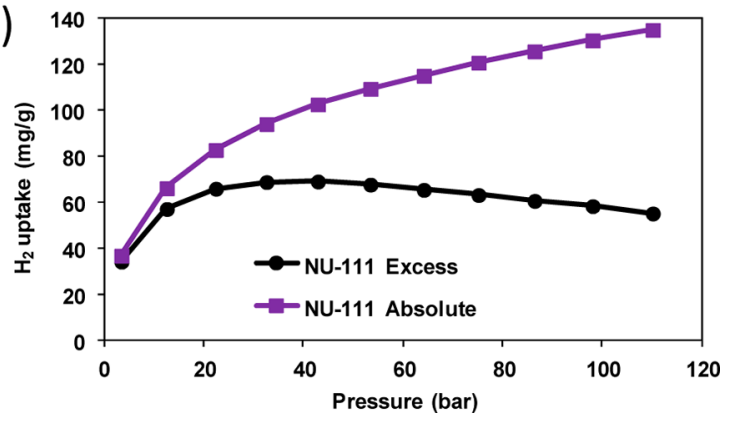

Figure 3. Adsorption isotherms of NU-111 at $77 \mathrm{~K}$ : (A) $\mathrm{N}_{2}$ isotherms; (B) excess $\mathrm{H}_{2}$ isotherms; (C) excess and absolute (total) $\mathrm{H}_{2}$ isotherms.

agreement with the experimental $\mathrm{H}_{2}$ measurements using the classical force field model ${ }^{34}$ (Figure 3B). Incorporating the Feynman-Hibbs (FH) corrections for quantum diffraction effects resulted in excellent agreement with the experimental isotherm. ${ }^{35}$

The stability of NU-111 was examined by running multiple cycles of high-pressure hydrogen adsorption at room temperature (see the SI), and it showed no loss of capacity. In addition, the $\mathrm{N}_{2}$ isotherms for NU-111 were measured before sending the sample to NREL and upon receiving the sample back from NREL (see the SI). The $\mathrm{N}_{2}$ isotherm showed no loss of porosity as a result of the shipping and measurements.

In conclusion, we have synthesized and characterized NU111, a stable and promising material for hydrogen storage at cryogenic temperatures. NU-111 was constructed from a linker whose arms each contain two triple-bond spacers in place of the one or two phenyl spacers in previously used linkers. Our results suggest that replacing the phenyl spacers with triplebond spacers may be a better strategy than using longer linkers to obtain higher-surface-area MOFs. The experimental and simulated data for NU-111 are in excellent agreement, which leads us to believe that a high-throughput computational screening approach, as recently described by Wilmer et al. ${ }^{36}$ for the related problem of high-pressure methane storage, may be sufficiently accurate to identify excellent candidate MOFs for 
high-pressure hydrogen storage. This may save experimentalists enormous amounts of time and effort as well as enable the efficient discovery and assessment of more promising MOFs such as NU-111.

\section{ASSOCIATED CONTENT}

\section{S Supporting Information}

General procedures, materials, and instrumentation; synthesis and characterization $\left({ }^{1} \mathrm{H}\right.$ and $\left.{ }^{13} \mathrm{C} \mathrm{NMR}\right)$ of $\mathbf{L H}_{6}(3)$; synthesis and X-ray crystallographic data (CIF) for NU-111; and sorption isotherms, BET analysis, and theoretical pore size distribution for NU-111. This material is available free of charge via the Internet at http://pubs.acs.org.

\section{AUTHOR INFORMATION}

\section{Corresponding Author}

o-farha@northwestern.edu; snurr@northwestern.edu; j-hupp@ northwestern.edu

\section{Author Contributions}

"O.K.F., C.E.W., and I.E. contributed equally.

\section{Notes}

The authors declare no competing financial interest.

\section{ACKNOWLEDGMENTS}

J.T.H., S.T.N., and R.Q.S. gratefully acknowledge the DOE Office of Energy Efficiency and Renewable Energy for primary financial support. O.K.F. acknowledges the Northwestern NSEC, which provided additional general support on MOF design and synthesis.

\section{REFERENCES}

(1) O’Keeffe, M.; Peskov, M. A.; Ramsden, S. J.; Yaghi, O. M. Acc. Chem. Res. 2008, 41, 1782.

(2) Férey, G. Chem. Soc. Rev. 2008, 37, 191.

(3) Horike, S.; Shimomura, S.; Kitagawa, S. Nat. Chem. 2009, 1, 695.

(4) Murray, L. J.; Dincă, M.; Long, J. R. Chem. Soc. Rev. 2009, 38, 1294

(5) Hu, Y. H.; Zhang, L. Adv. Mater. 2010, 22, E117.

(6) Sculley, J.; Yuan, D.; Zhou, H.-C. Energy Environ. Sci. 2011, 4, 2721.

(7) Hu, Y.; Xiang, S.; Zhang, W.; Zhang, Z.; Wang, L.; Bai, J.; Chen, B. Chem. Commun. 2009, 7551.

(8) Guo, Z.; Wu, H.; Srinivas, G.; Zhou, Y.; Xiang, S.; Chen, Z.; Yang, Y.; Zhou, W.; O'Keeffe, M.; Chen, B. Angew. Chem., Int. Ed. 2011, 50, 3178 .

(9) Li, J.-R.; Kuppler, R. J.; Zhou, H.-C. Chem. Soc. Rev. 2009, 38, 1477.

(10) An, J.; Geib, S. J.; Rosi, N. L. J. Am. Chem. Soc. 2010, 132, 38.

(11) Bae, Y.-S.; Farha, O. K.; Hupp, J. T.; Snurr, R. Q. J. Mater. Chem. 2009, 19, 2131.

(12) Britt, D.; Furukawa, H.; Wang, B.; Glover, T. G.; Yaghi, O. M. Proc. Natl. Acad. Sci. U.S.A. 2009, 106, 20637.

(13) Lee, J.; Farha, O. K.; Roberts, J.; Scheidt, K. A.; Nguyen, S. T.; Hupp, J. T. Chem. Soc. Rev. 2009, 38, 1450.

(14) Ma, L.; Abney, C.; Lin, W. Chem. Soc. Rev. 2009, 38, 1248.

(15) Kreno, L. E.; Leong, K.; Farha, O. K.; Allendorf, M.; Van Duyne,

R. P.; Hupp, J. T. Chem. Rev. 2012, 112, 1105.

(16) An, J.; Rosi, N. L. J. Am. Chem. Soc. 2010, 132, 5578.

(17) Horcajada, P.; Gref, R.; Baati, T.; Allan, P. K.; Maurin, G.; Couvreur, P.; Férey, G.; Morris, R. E.; Serre, C. Chem. Rev. 2012, 112, 1232.

(18) Lee, C. Y.; Farha, O. K.; Hong, B. J.; Sarjeant, A. A.; Nguyen, S. T.; Hupp, J. T. J. Am. Chem. Soc. 2011, 133, 15858.

(19) Kent, C. A.; Mehl, B. P.; Ma, L.; Papanikolas, J. M.; Meyer, T. J.; Lin, W. J. Am. Chem. Soc. 2010, 132, 12767.
(20) Getman, R. B.; Bae, Y.-S.; Wilmer, C. E.; Snurr, R. Q. Chem. Rev. 2012, 112, 703

(21) Suh, M. P.; Park, H. J.; Prasad, T. K.; Lim, D.-W. Chem. Rev. 2012, 112, 782 .

(22) http://www.caranddriver.com/news/mercedes-benz-f125concept-auto-shows (accessed March 17, 2012).

(23) Nouar, F.; Eubank, J. F.; Bousquet, T.; Wojtas, L.; Zaworotko, M. J.; Eddaoudi, M. J. Am. Chem. Soc. 2008, 130, 1833.

(24) Farha, O. K.; Yazaydın, A. Ö.; Eryazici, I.; Malliakas, C. D.; Hauser, B. G.; Kanatzidis, M. G.; Nguyen, S. T.; Snurr, R. Q.; Hupp, J. T. Nat. Chem. 2010, 2, 944.

(25) Yuan, D.; Zhao, D.; Sun, D.; Zhou, H.-C. Angew. Chem., Int. Ed. 2010, 49, 5357.

(26) Yan, Y.; Lin, X.; Yang, S.; Blake, A. J.; Dailly, A.; Champness, N. R.; Hubberstey, P.; Schröder, M. Chem. Commun. 2009, 1025.

(27) Yuan, D.; Zhao, D.; Zhou, H.-C. Inorg. Chem. 2011, 50, 10528.

(28) Yan, Y.; Yang, S.; Blake, A. J.; Lewis, W.; Poirier, E.; Barnett, S.

A.; Champness, N. R.; Schroder, M. Chem. Commun. 2011, 47, 9995.

(29) Furukawa, H.; Ko, N.; Go, Y. B.; Aratani, N.; Choi, S. B.; Choi, E.; Yazaydın, A. Ö.; Snurr, R. Q.; O’Keeffe, M.; Kim, J.; Yaghi, O. M. Science 2010, 329, 424

(30) Nelson, A. P.; Farha, O. K.; Mulfort, K. L.; Hupp, J. T. J. Am. Chem. Soc. 2008, 131, 458.

(31) Farha, O. K.; Hupp, J. T. Acc. Chem. Res. 2010, 43, 1166.

(32) Klein, N.; Senkovska, I.; Baburin, I. A.; Grünker, R.; Stoeck, U.; Schlichtenmayer, M.; Streppel, B.; Mueller, U.; Leoni, S.; Hirscher, M.; Kaskel, S. Chem.-Eur. J. 2011, 17, 13007.

(33) Han, D.; Jiang, F.-L.; Wu, M.-Y.; Chen, L.; Chen, Q.-H.; Hong, M.-C. Chem. Commun. 2011, 47, 9861.

(34) Levesque, D.; Gicquel, A.; Darkrim, F. L.; Kayiran, S. B. J. Phys.: Condens. Matter. 2002, 14, 9285.

(35) Liu, J.; Culp, J. T.; Natesakhawat, S.; Bockrath, B. C.; Zande, B.; Sankar, S. G.; Garberoglio, G.; Johnson, J. K. J. Phys. Chem. C 2007, $111,9305$.

(36) Wilmer, C. E.; Leaf, M.; Lee, C. Y.; Farha, O. K.; Hauser, B. G.; Hupp, J. T.; Snurr, R. Q. Nat. Chem. 2012, 4, 83. 